\title{
Preformed enzyme profiles of reference strains of gram- positive anaerobic cocci
}

\author{
D. A. MURDOCH, I. J. MITCHELMORE, R.A. NASH*, J.M. HARDIE* and S. TABAQCHALI
}

Department of Medical Microbiology, St Bartholomew's Hospital, London EC1A 7BE and Department of Oral Microbiology, The London Hospital, Turner Street, London E1 2AD

\begin{abstract}
Summary. The preformed (constitutive) enzyme profiles of 30 type strains and reference strains of gram-positive anaerobic cocci were determined with two commercial systems, RapID ANA and a prototype system from API. Both systems identified Peptostreptococcus anaerobius, Ps. asaccharolyticus, Ps. indolicus, Ps. magnus and Ps. micros accurately, except for one strain of Ps. magnus misidentified as Ps. micros by the RapID ANA system. The indole-negative, butyrate-producing cocci (classified at present as Ps. prevotii and Ps. tetradius) produced several different, unique patterns with the prototype API system, but the results with RapID ANA were often misleading. Eight strains of Hare group cocci produced previously described profiles. Four strains of streptococci produced profiles easily distinguished from those of the gram-positive anaerobic cocci. We conclude that most grampositive anaerobic cocci can be identified rapidly and reliably to the species level by their preformed enzyme profiles, providing that their underlying classification is sound. Problems were encountered with the butyrate-producing cocci, which appear to be a more heterogeneous group of organisms than is currently acknowledged; further taxonomic studies on these organisms are required.
\end{abstract}

\section{Introduction}

Gram-positive anaerobic cocci (GPAC) cause a wide spectrum of disease (Hare et al., 1952; Hare, 1967; Wren et al., 1977; Bourgault et al., 1980; Gorbach, 1985). However, taxonomic difficulties (Weiss, 1981; Ezaki et al., 1983; Huss et al., 1984) have delayed the development of identification techniques of practical use for the clinical laboratory. Gas-liquid chromatography (GLC) is accepted as the method of choice (Holdeman et al., 1977; Sutter et al., 1986), but it has limited powers of discrimination, and the equipment required is expensive and often not available in routine clinical laboratories.

In an earlier report (Murdoch et al., 1988), 69 strains of GPAC isolated from clinical specimens and identified by conventional tests (Sutter et al., 1986), were re-examined, separately and blindly, with two preformed (constitutive) enzyme systems--RapID ANA (Mercia Diagnostics, Guildford) and a prototype system from API (API Laboratory Products, Basingstoke). We have now tested a collection of type and reference strains,

Received 16 Dec. 1987; accepted 15 Feb. 1988. separately and blindly, together with four strains of micro-aerophilic and anaerobic streptococci.

\section{Materials and methods}

\section{Bacterial strains}

Thirty strains of GPAC and four strains of streptococci were coded at the London Hospital Medical College and examined blindly at St Bartholomew's Hospital; their identities were revealed when all tests had been completed and are shown in table I.

\section{Initial identification}

All organisms were characterised by the method of Sutter et al. (1986): Gram-stained films were examined; strains were tested for indole production (Indole Spot disks, Lab M, Bury) after incubation for $48 \mathrm{~h}$ on nonselective agar (Brucella Medium Base, Difco) with defibrinated horse blood (Oxoid) $6 \%$; they were tested for volatile fatty acid production by GLC (Holdeman et al., 1977) after incubation for $48 \mathrm{~h}$ in Robertson's Cooked Meat broth (Southern Group Laboratories, Hither Green, London); and their antibiotic sensitivities were tested with disks containing metronidazole $5 \mu \mathrm{g}$, vancomycin $5 \mu \mathrm{g}$ and SPS (sodium polyanethol sulphonate) $1 \mathrm{mg}$ (Oxoid). 
Table I. Identification of organisms

\begin{tabular}{|c|c|c|c|c|}
\hline Reference nos. of strains & Source & Received from & Received as & Identified as \\
\hline $\begin{array}{l}\text { NCTC } 11460 / \text { GIFU } 7882 / \\
\text { ATCC } 27337(\mathrm{~T})\end{array}$ & Unknown & T.E. & Ps. anaerobius & Ps. anaerobius \\
\hline DSM 20357 & Abscess & K.H.S. & Ps. anaerobius & Ps. anaerobius \\
\hline API A73 & Unknown & API & Ps. anaerobius & Ps. anaerobius \\
\hline GIFU 7877 & Vaginal discharge & T.E. & Ps. asaccharolyticus & Ps. asaccharolyticus \\
\hline $\mathrm{A} / \mathrm{C} 21$ & Unknown & M.W.D.W. & Ps. asaccharolyticus & Ps. asaccharolyticus \\
\hline NCTC $11029 / A T C C$ 29202(T) & Sheep rumen & A.B. & Ps. heliotrinreducens & Ps. heliotrinreducens \\
\hline $\begin{array}{l}\text { NCTC } 11088 / A T C C 29427 / \\
\text { GIFU } 7848(T)\end{array}$ & $\begin{array}{l}\text { Secretion of heifer with } \\
\text { summer mastitis }\end{array}$ & NCTC & Ps. indolicus & Ps. indolicus \\
\hline API A101 & Unknown & API & Ps. indolicus & Ps. indolicus \\
\hline ATCC 29328 & Abdominal wound & ATCC & Ps. magnus & Ps. magnus \\
\hline $\mathrm{A} / \mathrm{C} 6$ & Unknown & M.W.D.W. & Ps. magnus & Ps. magnus \\
\hline $\mathrm{A} / \mathrm{C} 8$ & Unknown & M.W.D.W. & Ps. magnus & Ps. magnus \\
\hline API A 110 & Unknown & API & Ps. magnus & Ps. magnus \\
\hline DW 1 & Unknown & G.L.F.S. & Ps. magnus & Ps. micros \\
\hline $\begin{array}{l}\text { DSM 20468/GIFU 7824/ } \\
\text { VPI 5464(T) }\end{array}$ & Purulent pleurisy & K.H.S./T.E. & Ps. micros & Ps. micros \\
\hline KP 1 & Unknown & G.L.F.S. & Ps. magnus & Ps. micros \\
\hline DSM 20358 & Abscess & K.H.S. & Ps. prevotii & $\mathrm{I}-\mathrm{B}+$ \\
\hline $\mathrm{A} / \mathrm{C} 5$ & Unknown & M.W.D.W. & Ps. prevotii & Ps. asaccharolyticus \\
\hline AN 8 & Unknown & G.L.F.S. & Ps. prevotii & Ps. asaccharolyticus \\
\hline GIFU 7874 & Unknown & T.E. & Ps. prevotii & I-B + \\
\hline STD 1 & Unknown & G.L.F.S. & Ps. prevotii & I-B + \\
\hline WGH 150 & Unknown & G.L.F.S. & Ps. prevotii & $\mathrm{I}-\mathrm{B}+$ \\
\hline NCTC 9801 & Unknown & NCTC & Hare group I & Ps. magnus \\
\hline NCTC 9803 & $\begin{array}{l}\text { Infected vagina in } \\
\text { puerperium }\end{array}$ & NCTC & Hare group III & Hare group III \\
\hline NCTC 9804 & Nose & NCTC & Hare group IV & Ps. magnus \\
\hline NCTC 9805 & Normal gingiva & NCTC & Hare group V & Veillonella parvula \\
\hline NCTC 9808 & Faeces & NCTC & Hare group VIIa & $\mathrm{I}-\mathrm{B}+$ \\
\hline NCTC 9811 & Normal vagina & NCTC & Hare group IX & Ps. magnus \\
\hline NCTC 9814 & $\begin{array}{l}\text { Infected vagina in } \\
\text { puerperium }\end{array}$ & NCTC & Hare group III & Hare group III \\
\hline NCTC 9820 & Normal nose & NCTC & Hare group VIII & $\mathrm{I}-\mathrm{B}+$ \\
\hline NCTC 9821 & Normal tonsil & NCTC & Hare group IX & Ps. micros \\
\hline NCDO 2227/ATCC 27335(T) & Unknown & NCDO & $S$. intermedius & S. intermedius \\
\hline NCTC $11323 / A T C C 27824(\mathrm{~T})$ & Lung abscess & NCTC & S. morbillorum & S. morbillorum \\
\hline SS 1091 & Unknown & L.V.H. & S. morbillorum & S. morbillorum \\
\hline $\begin{array}{l}\text { ACTC 33793/DSM 20469/ } \\
\text { VPI 0546/GIFU } 7866(\mathrm{~T})\end{array}$ & Unknown & ATCC/K.H.S. & S. parvulus & S. parvulus \\
\hline
\end{tabular}

I-B $+=$ indole-negative butyrate-producing coccus (classified at present as Ps. prevotii and Ps. tetradius).

$(\mathrm{T})=$ type strain of species.

Contributors: A.B. $\quad$ A. Bowen, formerly of Hope Hospital, Manchester.

T.E. T. Ezaki, Gifu University School of Medicine, Japan.

L.V.H. L.V. Holdeman, Virginia Polytechnic Institute, USA.

K.H.S. K.H. Schleifer, Technische Universitat Muenchen, Germany.

G.L.F.S. Gillian L.F. Smith, Bacteriology Department, Edinburgh University Medical School, Scotland.

M.W.D.W. M.W.D. Wren, Microbiology Department, North Middlesex Hospital, London.

API API Laboratories, Basingstoke, Hants.

ATCC American Type Culture Collection, Rockville, USA.

NCDO National Collection of Dairy Organisms, Reading, Berks.

NCTC National Collection of Type Cultures, Colindale, London.

\section{Inoculation of preformed enzyme kits}

Growth from a single colony was inoculated on to freshly prepared Columbia Agar (Oxoid) with horse blood $6 \%$ supplemented with vitamin $\mathrm{K} 0.1 \%$; the plates were then incubated anaerobically for $48 \mathrm{~h}$. The purity of the culture was checked at the same time. Kits were inoculated with a bacterial suspension of density McFarland standard no. 4 (bacterial count $c .10^{9} \mathrm{cfu} / \mathrm{ml}$ ) and incubated aerobically at $37^{\circ} \mathrm{C}$ for $4 \mathrm{~h}$. Reagents were 
then added and reactions interpreted according to the manufacturers' instructions. Tests substrates have been previously described (Murdoch et al., 1988).

The RapID ANA kits generated a six digit code which was interpreted with the RapID ANA Code Compendium. The enzyme profiles produced by the prototype API kits were interpreted by consulting data sheets previously constructed (Murdoch et al., 1988).

\section{Results}

Only strains of Streptococcus morbillorum and $S$. intermedius grew in an atmosphere of air $+\mathrm{CO}_{2} 5 \%$ within 7 days. These strains were resistant to metronidazole, but all others tested, including $S$. parvulus, were sensitive. All organisms tested were sensitive to vancomycin, except for NCTC strain 9805 of Hare group V (identified as Veillonella parvula).

The three strains of Peptostreptococcus anaerobius examined were all pleomorphic, chain-forming coccobacilli that were sensitive to SPS and produced isocaproic acid. They were correctly identified by both enzyme systems. None of the other organisms tested produced isocaproic acid or was sensitive to SPS.

Seven organisms were received as Ps. micros or Ps. magnus; all produced acetic acid only on GLC analysis. The organism received as Ps. micros and two organisms received as Ps. magnus were small, chain-forming cocci and were identified by both test systems as Ps. micros. Four organisms received as Ps. magnus were medium to large cocci arranged in clusters; RapID ANA misidentified one strain as Ps. micros because of a positive prolyl- $\beta$ naphthylamide reaction (cupule 3), but otherwise they were correctly identified as Ps. magnus.

Of the Hare group organisms tested (Hare, 1967), four produced only acetic acid on GLC analysis. Three of these were large cluster-forming cocci identified as Ps. magnus by both test systems: NCTC strain 9801 of Hare group I, NCTC strain 9804 of Hare group IV and NCTC strain 9811 of Hare group IX. NCTC strain 9821, however, which also belongs to Hare group IX, was a small chainforming coccus, which was identified in both systems as Ps. micros.

Ten organisms were received as Ps. asaccharolyticus, Ps. indolicus or Ps. prevotii; all produced butyric acid. Both strains of Ps. asaccharolyticus and both strains of Ps. indolicus were indole-positive by Indole Spot disks and were correctly identified by both test systems. Two strains received as $P S$. prevotii were also indole-positive; both systems identified them as Ps. asaccharolyticus. The four remaining strains received as $P$ s. prevotii were indole-negative; with the prototype API system they produced heterogeneous reaction profiles which were, however, distinct from those of other strains. The profiles generated by these four strains with RapID ANA were not unique: one organism was identified as $S$. morbillorum, two as Ps. tetradius and one as Ps. magnus.

Four Hare group organisms produced butyric acid. NCTC strain 9808 of Hare group VIIa was indole-negative; its enzyme profile was similar to organisms received as $P s$. prevotii. NCTC strain 9820 of Hare group VIII was also indole-negative; however, its enzyme profile was identical to that of Ps. asaccharolyticus except for the negative indole reaction. NCTC strains 9803 and 9814 of Hare group III were indole-positive, but the profiles produced by the prototype API system were completely different from those of Ps. asaccharolyticus or Ps. indolicus, i.e., sugars were utilised and aminopeptidase activity was almost absent. RapID ANA identified both strains as Ps. asaccharolyticus, but the profile codes generated (002254 and 022544) were slightly different from those of strains of $P S$. asaccharolyticus (typically 012544).

Ps. heliotrinreducens produced trace quantities of acetic acid and butyric acid; the RapID ANA profile code (052401) and the API profile were unique. NCTC strain 9805 (Hare group V) was a small gram-negative coccus that produced propionic acid; it was identified as $V$. parvula by both enzyme systems. The four strains of streptococci produced enzyme profiles easily distinguished from those of other species examined. The code generated by the type strain of $S$. parvulus, which is not included in the RapID ANA Code Compendium, was 612560 .

\section{Discussion}

Analysis of acid end-products by GLC is acknowledged to be a reliable and important part of the identification of anaerobic cocci (Holdeman et al., 1977; Sutter et al., 1986). In this study, we found complete agreement between the identity of strains indicated by GLC analysis and identification by means of the preformed enzyme profile. There was also $90 \%$ agreement between identification based on the enzyme profile and the identity of the organism as sent to us. We conclude that preformed enzyme profiles are a valuable method for the identification of gram-positive anaerobic cocci, especially for laboratories with limited facilities.

At present, GPAC strains that produce isocaproic acid are all described as Ps. anaerobius, whereas 
Characteristic reaction in cupule number

\begin{tabular}{|c|c|c|c|c|c|c|c|c|c|c|c|c|c|c|c|c|c|c|c|c|c|c|c|c|c|c|c|c|c|c|}
\hline Reference nos. of strains & Species & 1 & 4 & 5 & 8 & 9 & 10 & 11 & 12 & 13 & 14 & 15 & 16 & 17 & 18 & 19 & 20 & 21 & 22 & 23 & 24 & 25 & 26 & 27 & 28 & 29 & 30 & 31 & 32 & 33 \\
\hline $\begin{array}{l}\text { NCTC } 11460 / \\
\text { GIFU } 7882 / \\
\text { ATCC } 27337 \text { (T) }\end{array}$ & Ps. anaerobius & - & - & + & - & - & - & - & + & - & - & - & + & - & - & - & - & $\mp$ & + & - & - & - & - & - & - & - & - & $\mp$ & - & - \\
\hline API A73 & Ps. anaerobius & - & - & + & - & - & - & - & + & $\mp$ & - & - & + & - & - & - & - & - & + & - & - & - & - & - & - & - & - & $\overline{-}$ & - & - \\
\hline DSM 20357 & Ps. anaerobius & - & - & + & - & - & - & - & \pm & $\mp$ & - & - & + & - & - & - & - & - & + & - & - & - & - & - & - & - & - & $\mp$ & - & - \\
\hline GIFU 7877 & Ps. asaccharolyticus & - & - & - & - & - & - & - & $\overline{-}$ & - & - & - & - & - & + & - & - & + & - & + & $\mp$ & - & - & + & - & + & - & \pm & - & - \\
\hline AN 8 & Ps. asaccharolyticus & - & - & - & - & - & - & - & - & - & - & - & - & - & + & - & - & + & - & + & - & - & - & \pm & - & + & - & $\bar{\mp}$ & - & - \\
\hline $\mathrm{A} / \mathrm{C} 5$ & Ps. asaccharolyticus & - & - & - & - & - & - & - & - & - & - & - & - & - & + & - & - & + & - & \pm & - & - & - & \pm & - & + & - & \pm & - & - \\
\hline $\mathrm{A} / \mathrm{C} 21$ & Ps. asaccharolyticus & - & - & - & - & - & - & - & - & - & - & - & - & - & + & - & - & + & - & $\overline{ \pm}$ & - & - & - & \pm & - & + & - & $\overline{\bar{\mp}}$ & - & - \\
\hline NCTC 9803 & Hare group III & - & - & \pm & - & - & - & - & + & + & - & - & + & - & + & - & - & - & - & $\overline{-}$ & - & - & - & $\overline{-}$ & $\mp$ & - & - & $\mp$ & - & - \\
\hline NCTC 9814 & Hare group III & - & - & 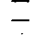 & - & - & - & - & + & + & - & - & + & - & + & - & - & - & - & - & - & - & - & - & - & - & - & - & - & - \\
\hline $\begin{array}{l}\text { ATCC } 29427 / \text { NCTC } \\
11088 / G I F U ~ 7848(T)\end{array}$ & Ps. indolicus & - & - & - & - & - & - & - & - & - & - & - & - & - & + & - & + & + & - & + & $\mp$ & - & - & $\mp$ & - & \pm & - & \pm & - & - \\
\hline API A101 & Ps. indolicus & - & - & - & - & - & - & - & - & - & - & - & - & - & + & - & \pm & + & - & + & - & $\bar{z}$ & - & \pm & - & \pm & $\mp$ & \pm & + & - \\
\hline ATCC 29328 & Ps. magnus & \pm & - & - & - & - & - & - & - & - & - & - & - & - & - & - & $\mp$ & + & - & \pm & \pm & $\mp$ & - & $\bar{t}$ & + & $\overline{-}$ & \pm & $\bar{t}$ & \pm & - \\
\hline A/C 6 & Ps. magnus & $\overline{\bar{\mp}}$ & - & - & - & - & - & - & - & - & - & - & $\mp$ & - & - & - & $\mp$ & + & - & $\overline{\overline{\bar{T}}}$ & $\overline{+}$ & - & - & + & + & $\mp$ & \pm & \pm & $\overline{\overline{7}}$ & + \\
\hline $\mathrm{A} / \mathrm{C} 8$ & Ps. magnus & $\mp$ & - & - & - & - & - & - & - & - & - & - & \pm & - & - & - & \pm & + & - & \pm & \pm & - & - & + & + & $\mp$ & $\bar{t}$ & $\overline{+}$ & \pm & - \\
\hline API A 110 & Ps. magnus & \pm & - & - & - & - & - & - & - & - & - & - & $\overline{-}$ & - & - & - & $\overline{\bar{\mp}}$ & + & - & \pm & + & - & - & + & + & - & \pm & \pm & \pm & - \\
\hline NCTC 9801 & $\begin{array}{l}\text { Ps. magnus } \\
\text { (Hare group I) }\end{array}$ & $\overline{ \pm}$ & - & - & - & - & - & - & - & - & - & - & $\mp$ & - & - & - & $\mp$ & + & - & $\overline{\bar{F}}$ & \pm & - & - & + & + & - & $\mp$ & \pm & $\bar{\mp}$ & - \\
\hline NCTC 9804 & $\begin{array}{l}\text { Ps. magnus } \\
\text { (Hare group IV) }\end{array}$ & $\mp$ & - & - & - & - & - & - & - & - & - & - & $\mp$ & - & - & - & $\mp$ & + & - & $\mp$ & \pm & - & - & + & + & $\mp$ & \pm & \pm & $\mp$ & - \\
\hline NCTC 9811 & $\begin{array}{l}\text { Ps. magnus } \\
\text { (Hare group IX) }\end{array}$ & + & - & - & - & - & - & - & - & - & - & - & $\mp$ & - & - & - & - & + & - & \pm & \pm & - & - & + & + & $\mp$ & $\mp$ & \pm & $\mp$ & - \\
\hline $\begin{array}{l}\text { DSM 20468/ } \\
\text { VPI 5464/ } \\
\text { GIFU 7824(T) }\end{array}$ & Ps. micros & - & - & - & - & - & - & - & - & - & - & - & - & - & - & - & + & + & + & + & + & + & + & + & + & + & + & + & + & - \\
\hline DW 1 & Ps. micros & - & - & - & - & - & - & - & - & - & - & - & - & - & - & - & + & + & + & + & + & + & \pm & + & + & + & + & + & + & - \\
\hline KP 1 & Ps. micros & - & - & - & - & - & - & - & - & - & - & - & - & - & - & - & + & + & + & + & \pm & + & \pm & + & + & + & + & \pm & + & - \\
\hline NCTC 9821 & Ps. micros(Hare group IX) & - & - & - & - & - & - & - & - & - & - & - & - & - & - & - & + & + & + & + & \pm & + & $\overline{+}$ & + & + & \pm & + & $\bar{t}$ & + & - \\
\hline $\begin{array}{l}\text { NCTC } 11029 / \\
\text { ATCC } 27337(\mathrm{~T})\end{array}$ & $\begin{array}{l}\text { Ps. heliotrin- } \\
\text { reducens }\end{array}$ & + & - & - & - & - & - & - & - & - & - & - & - & - & - & - & - & - & + & + & $\overline{-}$ & + & - & + & - & \pm & + & + & + & - \\
\hline DSM 20358 & $\mathbf{I}-\mathbf{B}+$ & - & - & \pm & - & - & - & + & + & \pm & - & - & \pm & + & - & - & - & $\mp$ & - & $\mp$ & - & $\mp$ & - & $\mp$ & - & $\mp$ & $\mp$ & $\mp$ & $\mp$ & - \\
\hline GIFU 7874 & $\mathbf{I}-\mathbf{B}+$ & $\mp$ & $\mp$ & - & $\mp$ & $\mp$ & - & - & + & + & - & - & + & - & - & - & $\mp$ & + & - & $\mp$ & - & - & - & + & \pm & - & $\mp$ & \pm & - & - \\
\hline STD 1 & I-B + & \pm & - & - & - & $\mp$ & + & - & + & \pm & - & - & + & - & - & - & + & + & - & \pm & $\mp$ & - & - & + & \pm & - & $\mp$ & $\frac{1}{\bar{x}}$ & $\mp$ & - \\
\hline WGH 150 & $\mathbf{I}-\mathbf{B}+$ & $\bar{t}$ & - & - & - & - & - & - & \pm & $\mp$ & - & - & - & - & - & - & - & + & - & $\bar{t}$ & $\mp$ & - & - & + & $\overline{\bar{\mp}}$ & - & $\mp$ & $\mp$ & $\mp$ & + \\
\hline NCTC 9808 & $\begin{array}{l}\text { I-B+ } \\
\text { (Hare group VIIa) }\end{array}$ & - & - & $\mp$ & - & - & - & - & $\overline{+}$ & + & - & - & + & - & - & - & - & + & - & \pm & \pm & - & - & \pm & + & - & - & \pm & - & - \\
\hline NCTC & Hare group VIII & - & - & - & - & - & - & - & - & - & - & - & - & - & - & - & - & + & - & + & - & - & - & \pm & - & $\mp$ & - & $\mp$ & - & - \\
\hline NCTC 9805 & $\begin{array}{l}\text { V. parvula } \\
\text { (Hare group V) }\end{array}$ & \pm & - & - & - & - & - & - & - & - & - & - & - & - & - & + & - & - & - & - & - & - & - & $\bar{z}$ & $\mp$ & - & - & - & - & - \\
\hline
\end{tabular}




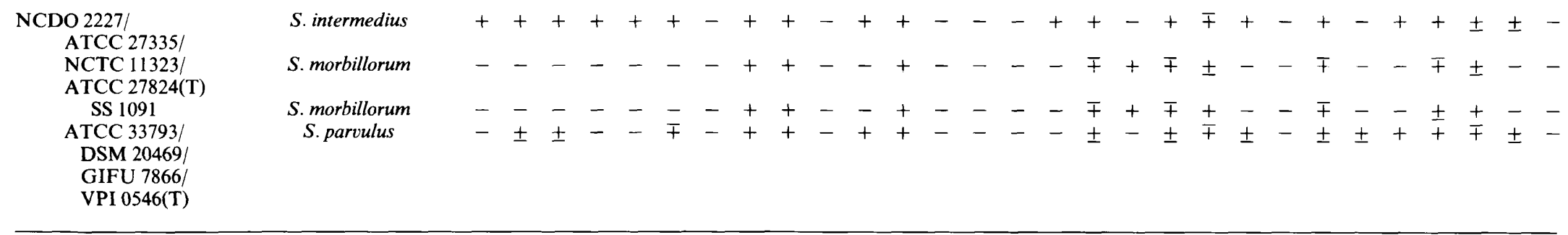

The results of reactions in cupules 2,3,5 and 6 were always negative and have been omitted.

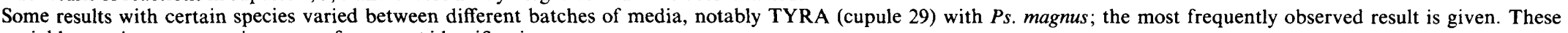
variable reactions were not important for correct identification.

$+=$ strongly positive; $\quad \pm=$ weakly positive $; \quad \bar{F}=$ very weakly positive; $\quad-=$ negative

$\mathrm{I}-\mathrm{B}+$ indole-negative butyrate-producing coccus. 
GPAC strains that produce only acetic acid are identified as Ps. magnus or Ps. micros according to the size of the coccus (Sutter et al., 1986). Our results and those of an earlier study (Murdoch $e t$ al., 1988) are consistent with that classification. However, enzyme profiles reveal considerably greater heterogeneity in the butyrate-producing cocci, and, in particular, suggest that indole production is not a reliable test for their identification.

Indole-positive, butyrate-producing cocci are classified at present as either Ps. asaccharolyticus or Ps. indolicus (Ezaki et al., 1983; Sutter et al., 1986), but reliable tests and conditions for their differentiation were not fully described by these authors. Their preformed enzyme profiles are very similar (Murdoch et al., 1988), but Ps. indolicus appears to be distinguished by a strongly positive alkaline phosphatase reaction, detectable in both enzyme systems. However, NCTC strains 9803 and 9814 of Hare group III, which would be described by Sutter et al. (1986) as Ps. asaccharolyticus, produce completely different profiles, almost identical to two 'indole-positive saccharolytic' clinical isolates previously described (Murdoch et al., 1988). It is likely, therefore, that Hare group III is representative of a previously undescribed species of indole-positive butyrate-producing coccus.

It has already been noted that the enzyme profile of NCTC strain 9820 (Hare group VIII) is almost identical with that of four reference strains of $P S$. asaccharolyticus (table II), differing only by the indole reaction. DNA-DNA hybridisation studies have provided evidence that NCTC strain 9820 is homologous with DSM strain 20364, a reference

\section{REFERENCES}

Bourgault A-M, Rosenblatt J E, Fitzgerald R H 1980 Peptococcus magnus; a significant human pathogen. Annals of Internal Medicine 93: 244.

Ezaki T, Yamamoto N, Ninomiya K, Suzuki S, Yabuuchi E 1983 Transfer of Peptococcus indolicus, Peptococcus asaccharolyticus, Peptococcus prevotii and Peptococcus magnus to the genus Peptostreptococcus and proposal of Peptostreptococcus tetradius sp. nov. International Journal of Systematic Bacteriology 33: 683 .

Gorbach S L 1985 Anaerobic cocci. In: Mandell G L et al. (eds) The principles and practice of infectious diseases, 2nd edn, John Wiley, New York, pp. 1373-1375.

Hare R, Wildy P, Billett F S, Twort D N 1952 The anaerobic cocci: gas formation, fermentation reactions, sensitivity to antibiotics and sulphonamides. Classification. Journal of Hygiene 50: 295-319.

Hare R 1967 The anaerobic cocci. In: Waterson A P (ed) Recent advances in medical microbiology. Churchill, London, pp 284-317. strain of Ps. asaccharolyticus (Huss et al., 1984). The enzyme profile of NCTC strain 9820 is also very similar to that of four clinical isolates of indolenegative cocci previously described (Murdoch et al., 1988). We suggest, therefore, that indolenegative strains of Ps. asaccharolyticus occur. If this is correct, the indole reaction would appear to be of little value. The remaining indole-negative, butyrate-producing cocci (originally designated as $P S$. prevotii) did not produce a consistent pattern. Organisms classified as $P$ s. prevotii and $P$ s. tetradius are almost certainly heterogeneous, as acknowledged by Ezaki et al. (1983) in their original description of Ps. tetradius; performed enzyme profiles may assist in resolving the taxonomy of this group.

Several representative streptococci were studied because strains of some species are micro-aerophilic ( $S$. morbillorum and $S$. intermedius) or even obligately anaerobic ( $S$. parvulus). The micro-aerophilic species should not be misidentified as anaerobic cocci because they are resistant to metronidazole; however, the type strain of $S$. parvulus was a small chain-forming coccus, sensitive to metronidazole, and therefore easily confused with Ps. micros. This study suggests that $S$. parvulus can be distinguished by means of its enzyme profile.

Many of the strains studied were very kindly donated by colleagues in other laboratories. We are grateful to Mrs Shirley Lawrence and Miss Leslie Theobald for laboratory assistance, to Mrs Sandy Gale and Mrs Cathy Whitfield for secretarial assistance and to API Laboratories for donating prototype kits.

Holdeman L V, Cato E P, Moore W E C 1977 Anaerobic laboratory manual, 4th edn. Anaerobe Laboratories, Virginia Polytechnic Institute and State University, Blacksburg, VA, USA.

Huss V A R, Festl H, Schleifer K H 1984 Nucleic acid hybridization studies and deoxyribonucleic acid base compositions of anaerobic gram-positive cocci. International Journal of Systematic Bacteriology 34: 95-101.

Murdoch D A, Mitchelmore I J, Tabaqchali S 1988 Identification of gram positive anaerobic cocci by use of systems for detecting preformed enzymes. Journal of Medical Microbiology 27: 65-70.

Sutter V L, Citron D M, Edelstein M A C, Finegold S M 1985 Wadsworth anaerobic bacteriology manual, 4th edn. Star Publishing Co., Los Angeles, CA, USA.

Weiss N 1981 Cell wall structure of anaerobic cocci. Revue de l'Institut Pasteur de Lyon 14: 53-59.

Wren M W D, Baldwin A W F, Eldon C P, Sanderson P J 1977 The anaerobic culture of clinical specimens: a 14 month study. Journal of Medical Microbiology 10: 49-61. 